\title{
EFFECT OF VEHICLE LIGHT ON THE NANOSTRUCTURE OF PARTICULATE MATTERS EMITTED FROM DIESEL AND GASOLINE VEHICLES
}

\author{
MEISAM AHMADI GHADIKOLAEI ${ }^{1}$, PAK KIN WONG ${ }^{1}$, \\ SHOU HAO CHEN ${ }^{1}$, KAR WEI NG ${ }^{2} \&$ JIN CHENG XU ${ }^{2}$ \\ ${ }^{1}$ Department of Electromechanical Engineering, University of Macau, Macau \\ ${ }^{2}$ Institute of Applied Physics and Materials Engineering, University of Macau, Macau
}

\begin{abstract}
Particulate matters (PMs) are currently one of the main threats to human health and the environment. The transportation sector, particularly diesel and gasoline vehicles, among others, has a significant contribution to the global PM level. While the PMs from vehicles have serious and dangerous negative impacts on human health due to their toxicity components along with their small diameters (penetrating more deeply into the human's body). Therefore, researchers are seeking some solutions to reduce the concentration of PMs from vehicles as well as investigate those parameters affecting the PM properties upon their release from the exhaust pipes. Vehicle light, among others, could be a factor for changing the PM properties, while no comprehensive study can be found in the literature in this field. This study is therefore presented to explore the impact of vehicle light emitted from halogen headlights (as an abundant one available on the market) on the nanostructure of both fresh and aged PMs from a diesel vehicle under an idle condition (fresh PMs), a diesel particulate filter (aged PMs), and a gasoline vehicle exhaust pipe (engine was off, aged PMs). The samples were exposed to the light for 6 hours at a distance of $0.1 \mathrm{~m}$. Based on the results obtained from a scanning transmission electron microscope (STEM) and a scanning electron microscope (SEM), the vehicle light changes the nanostructure of PMs by reductions in fringe length $(25.0 \%, 8.4 \%$, and $7.1 \%)$ and fringe tortuosity $(3.0 \%, 2.9 \%$, and $1.8 \%)$, and enlargements in fringe separation distance $(3.0 \%, 2.3 \%$, and $1.9 \%)$, core size/shell size ratio $(67.6 \%$, $36.9 \%$, and $62.1 \%$ ), and core size/particle size ratio $(38.4 \%, 25.0 \%$, and $33.3 \%$ ), resulting in enlargements in particles diameters from 21.2 to $30.4 \mathrm{~nm}$, from 32.3 to $33.5 \mathrm{~nm}$, and from 27.1 to $29.8 \mathrm{~nm}$ for all three samples tested, respectively.
\end{abstract}

Keywords: air pollution control, environmental issue, human health, properties of particulate matters, vehicle headlights, vehicular emission control.

\section{INTRODUCTION}

Nowadays, approximately nine out of ten people in the world breathe in contaminated air containing a high level of pollutants, particularly particulate matters with a diameter of 2.5 microns or smaller $\left(\mathrm{PM}_{2.5}\right)$, in both ambient (outdoor) and household (indoor) areas. It causes heart disease, stroke, chronic obstructive pulmonary disease, lung cancer, acute respiratory infections, and other diseases/problems, resulting in shortening the human's life on average by 20 months and approximately 7 million global deaths per year, and making the PMs as one of the serious leading risk factors for global mortality [1]-[4]. In addition, PMs have a negative impact on both the ground and underwater environments and even animals' lives due to their suspending potential in air and solubility potential in water [5].

It is known that, on the one hand, the negative impact of PMs on human health and the environment is mostly due to their toxicity components [6]-[11]. But on the other hand, the magnitude of these negative components on human health and the environment can/will be more or less, if the number, size, morphology, nanostructure, and mass of PMs be changed [12], [13]. For instance, if the PMs become smaller, they can penetrate more deeply into the human's and animal's bodies through the respiratory passageways, resulting in more damaging the lung and other tissues in comparison with the larger ones [12], [14]. Regarding 
the environment, small PMs can be suspended longer in air, are more transportable, can be dissolved easily and faster in water and rain, have lower solar radiation absorption rate and less reacting potential with other types of atmospheric constituents, etc. [5], [15], [16]. Thus, there is a need for more concern in this field, particularly in the size and structure of PMs. Various parameters and conditions have impacts on the size and structure of PMs, including types and sources of PMs (from transportation, construction, and industrial sectors, etc.), ambient temperature, humidity, wind, light, etc., PMs age (fresh or mature) and suspension period, along with other parameters/conditions. The transportation fleet, among others, is one the main sources of PMs that are very close to the human's living areas. Therefore, there is a need for more attention on the PMs emitted from the transportation fleet and studying the possible parameters affecting their properties, particularly in the size and structure.

However, unfortunately, the existing literature regarding the properties of PMs emitted from the transportation fleet, particularly diesel and gasoline vehicles along with their particulate filters, is not rich enough as needed and further studies are still required (latest review papers in 2020-2021 [17]-[20]) to find some suitable and applicable solutions for reducing their negative impacts on human health and the environment. Therefore, this study is presented to enrich the literature by investigating the influence of light emitted from a vehicle headlight (Halogen type as an abundant one), on the nanostructure of fresh and mature PMs, including fresh PMs from a diesel vehicle and mature PMs deposited in a diesel particulate filter (DPF) and a gasoline vehicle exhaust pipe. Investigating the nanostructure of primary particles is one of the best methods for exploring and modelling the important parameters of PMs such as morphology and size. The content of this research is useful for getting information from the contaminated places containing a high level of PMs such as car parks (closed areas), tunnels, urban canyons, etc., when several vehicle headlights are switched on for a long period of time during the night and day and the PMs fly around them.

\section{METHODOLOGY}

Three PM sampling locations from one diesel vehicle operating under an idle condition, and inside of a diesel particulate filter and a gasoline vehicle exhaust pipe (engine was off) were selected in this research as shown in Fig. 1. Firstly, the PM samples were directly collected on the $3 \mathrm{~mm}$ copper transmission electron microscope (TEM) grids. In the next step, the samples were exposed to a vehicle headlight (Halogen type, $12 \mathrm{~V} 65 / 55 \mathrm{~W}$ ) under the low beam condition for 6 hours at a distance of $0.1 \mathrm{~m}$ (light intensity of $438 \mathrm{~W} / \mathrm{m}^{2}$ ) as shown in Fig. 2. We selected halogen headlight because this type is one of the abundant types available on the market. A scanning transmission electron microscope (STEM) (model FEI Talos F200S; resolution of $0.16 \mathrm{~nm}$ ) and a scanning electron microscope (SEM) (model ZEISS Sigma; resolution of $1.0 \mathrm{~nm}$ ) were employed to analyse the samples before and after exposure to the vehicle light and an image processing software (Image-Pro Plus 6.0, Media Cybernetics) were used to process the results (images).

To obtain highly accurate results, 30 primary particles were chosen from the images for analysing their nanostructure. Fringe length, fringe separation distance, fringe tortuosity, and core size/shell size and core size/particle size ratios refer to the nanostructure of particles in this research, as illustrated in Fig. 3. Detailed information regarding the PM sampling and analysis procedure is available in Mao et al. [21] and Ghadikolaei et al. [22]. The experimental results were checked by the two-tailed student's T-test under a 95\% significance level $(\mathrm{p}<0.05)$. Uncertainty at a $95 \%$ confidence level was calculated according to Moffat [23]. 
Outside of diesel vehicle exhaust pipe (engine ran at idle condition)
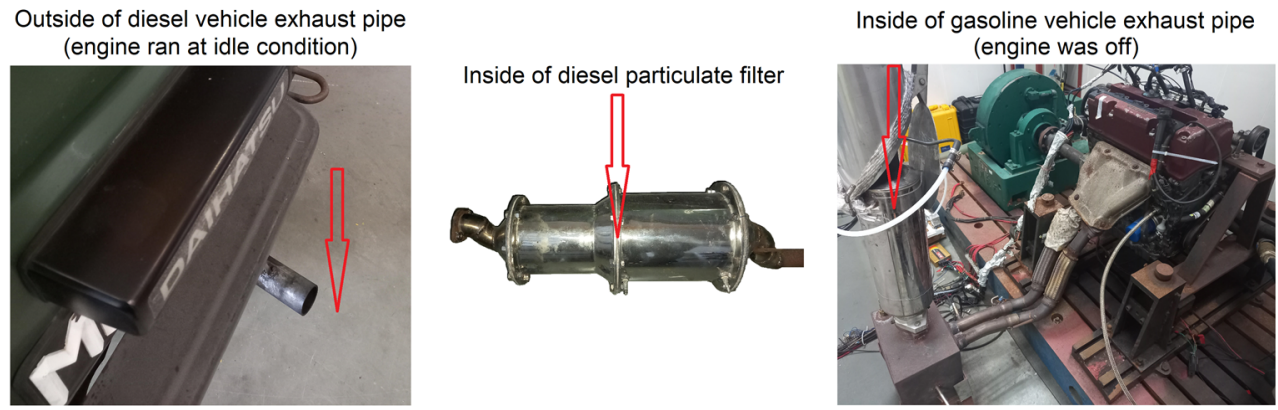

Figure 1: PM sampling locations for this research.

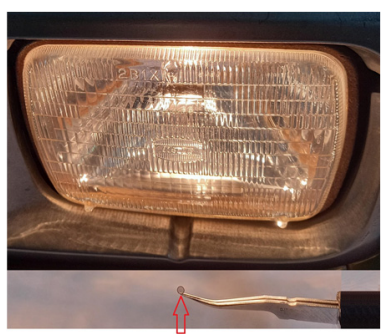

3mm TEM grid containing PMs, exposed to vehicle light for $6 \mathrm{hrs}$ at a distance of $0.1 \mathrm{~m}$

Figure 2: Exposure distance of TEM grids containing PMs to vehicle light.

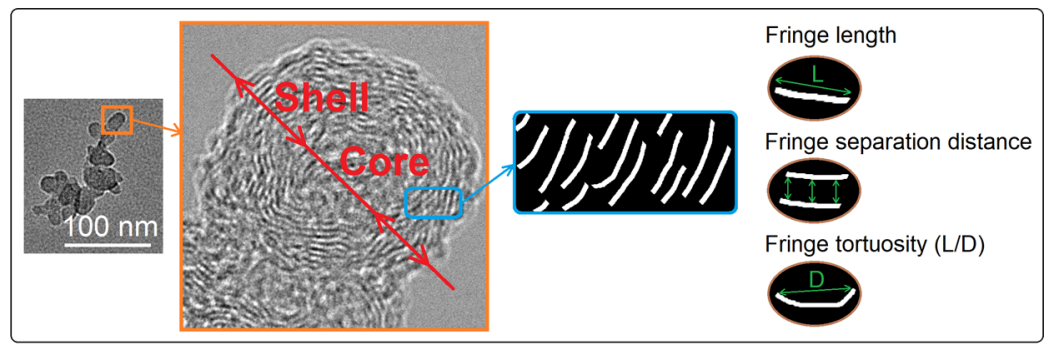

Figure 3: Nanostructure parameters of primary particles investigated in this study.

\section{RESULTS AND DISCUSSION}

The idea for exploring the impact of vehicle light on the properties of PMs has come from our observation on the changes in the shape, structure, and size of PMs due to exposure to the electron beam for a short period (few seconds to minutes, see Fig. 4) during operating the SEM. Therefore, the vehicle light for a longer period of use (several hours at the night and even in the daytime in contaminated places like car parks, tunnels, roadsides, etc.) may also change the PM properties. Thus, we performed several tests to investigate the effect of vehicle light on the nanostructure of fresh and mature PMs from diesel and gasoline vehicles 


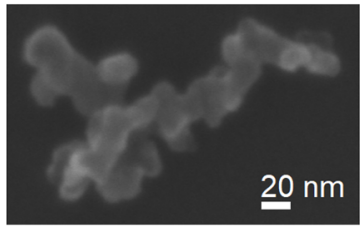

$0 \mathrm{~min}$

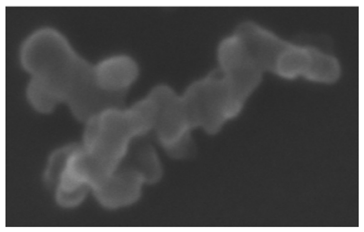

$3 \mathrm{~min}$

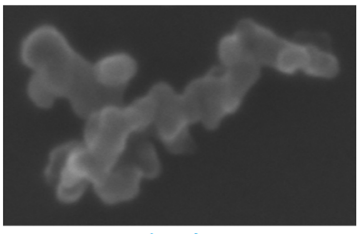

$1 \mathrm{~min}$

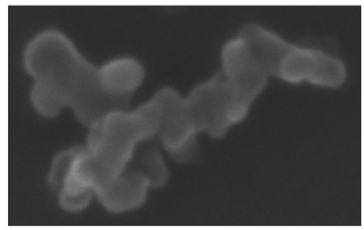

$4 \mathrm{~min}$

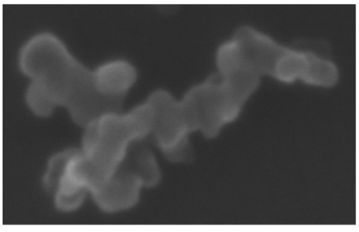

2 min

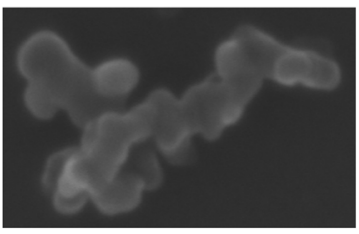

$5 \mathrm{~min}$

Figure 4: Changes in the shape, structure, and size of PMs emitted from the diesel vehicle at an idle condition, due to exposure to the electron beam of SEM from $0 \mathrm{~min}$ (original PMs) until 5 min under a low accelerating voltage of $5 \mathrm{kV}$.

for an exposure period of 6 hours at a distance of $0.1 \mathrm{~m}$. The fresh PMs in this research were directly sampled from the engines right after their generation from the engine; while the mature PMs refer to those PMs that are produced from the engines but are deposited in some places (i.e., diesel particulate filter or exhaust pipe) for a long period of time, e.g., more than 5 years for the PM samples deposited in the diesel particulate filter and approximately 6 months for the gasoline vehicle exhaust pipe, for this research.

It can be seen from Fig. 5 that the vehicle light has the potential to change the morphology of the primary particles by creating edge defects for all three PM samples, while the fresh PM sample receives the highest changes. It is because the vehicle light increases the ambient temperature, among other factors, resulting in melting the volatile components in the primary particles and forming disorder nanostructure and defects, particularly at the edge sides (Fig. 5) along with shortening the size of fringe length by $25.0 \%$ for the fresh PMs, $8.4 \%$ for the aged PMs of DPF, and 7.1\% for the aged PMs of gasoline vehicle exhaust pipe (Fig. 6). Also, there is a slight increase (significant according to T-test checking) in the fringe separation distance by $3.0 \%$ for the fresh PMs, $2.3 \%$ for the aged PMs of DPF, and $1.9 \%$ for the aged PMs of gasoline vehicle exhaust pipe. Regarding the fringe tortuosity, Fig. 6 reveals that the exposure to the vehicle light has a slight decrease impact on the fringe tortuosity by $3.0 \%$ for the fresh PMs, $2.9 \%$ for the aged PMs of DPF, and 1.8\% for the aged PMs of gasoline vehicle exhaust pipe. Since the volatile components in the particles are melted and spread, the particles will have a shorter fringe length with larger carbon layers distance (fringe separation distance) and more straight carbon layers (smaller fringe tortuosity).

Vehicle light, also, causes increases in both core size/shell size and core size/particle size ratios by $67.6 \%$ and $38.4 \%$ for the fresh PMs, $36.9 \%$ and $25.0 \%$ for the aged PMs of DPF, and $62.1 \%$ and $33.3 \%$ for the aged PMs of gasoline vehicle exhaust pipe, respectively, as shown in Fig. 7. Since the core has a disordered structure, very small fringe length, and weak connections between the carbon layers, the exposure to the vehicle light can make it bigger compared with the shell side, resulting in having higher core size/shell size and core size/particle size ratios. It can be understood from the results that the fresh PMs, in 


\section{Before exposure to vehicle light}

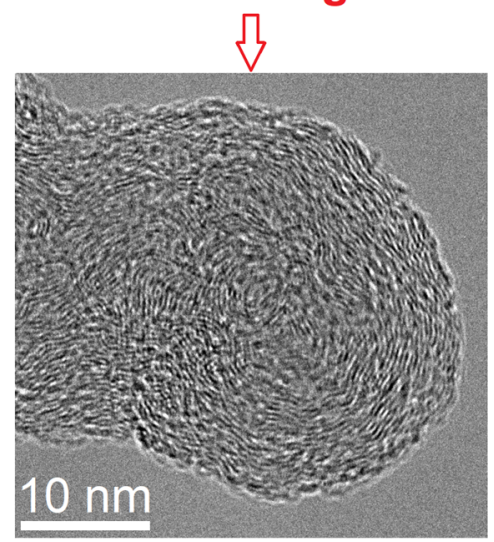

PMs from diesel vehicle exhaust (fresh PMs)

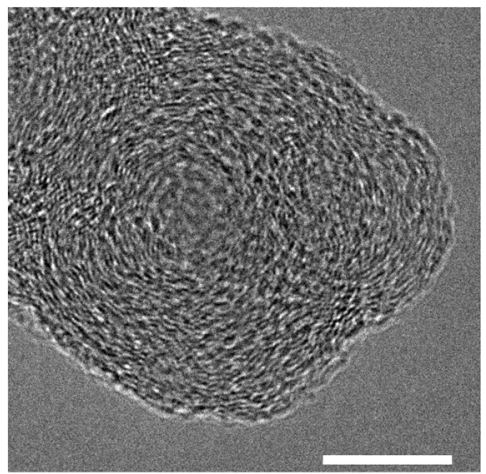

After exposure to vehicle light

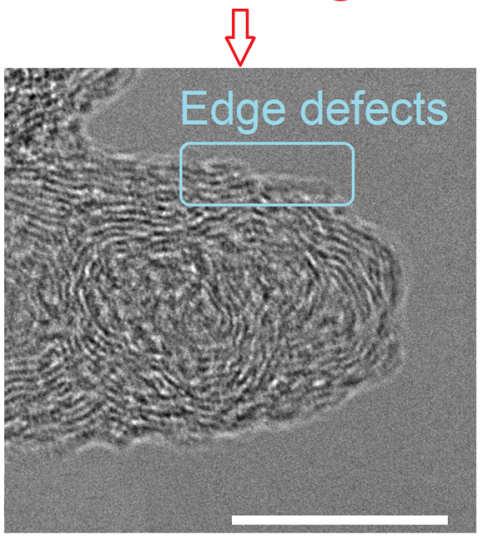

PMs deposited in diesel particulate filter (aged PMs)
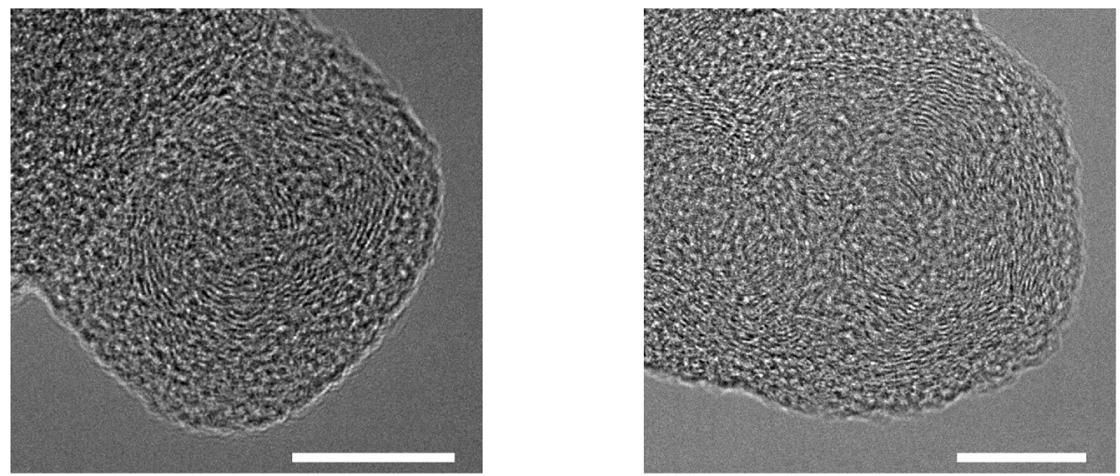

PMs deposited in gasoline vehicle exhaust pipe (aged PMs)

Figure 5: Effect of vehicle light on the morphology of primary particles. 

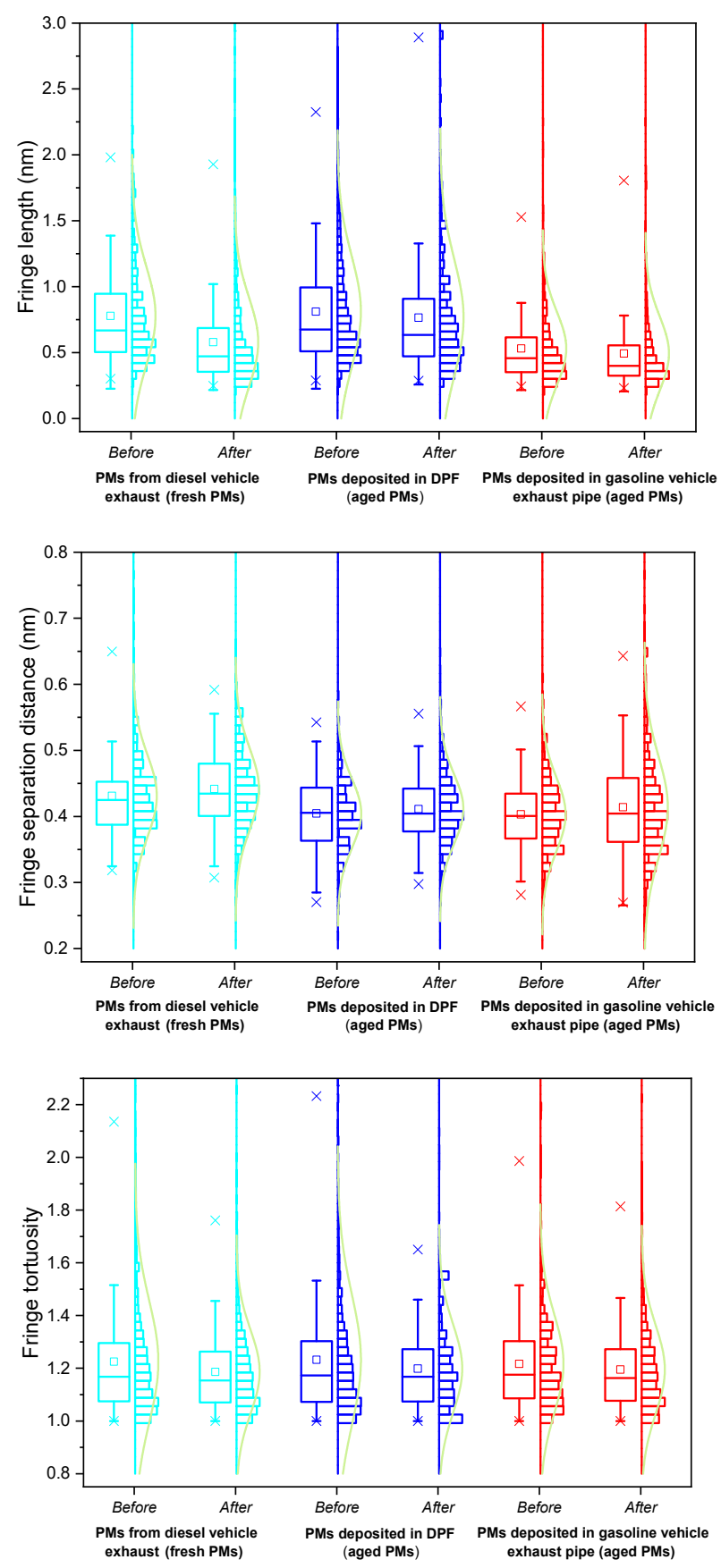

Figure 6: Distributions of fringe length, separation distance, and tortuosity along with box charts for different PM samples before and after exposure to vehicle light. Note: "error bar" stands for the outlier, " $\times$ " stands for 1 and $99 \%$ of the values, "line in the box" stands for the median value, " $\square$ " stands for the mean value, and "curve" stands for the normal distribution fitting curve. 

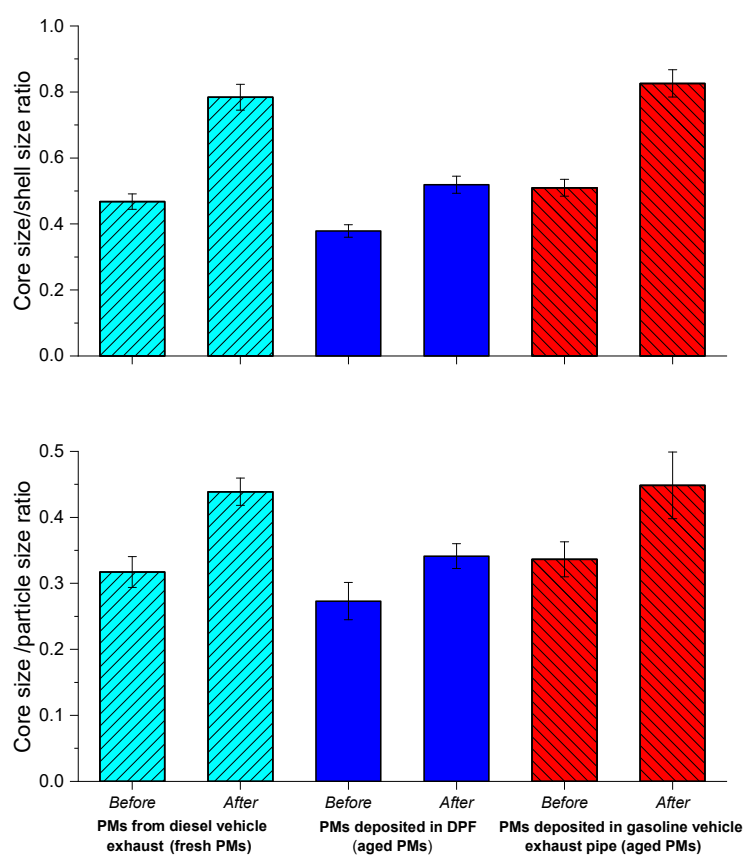

Figure 7: Core size/shell size and core size/particle size ratios for different PM samples before and after exposure to the vehicle light.

comparison with the aged PMs, receive the highest changes after their exposure to the vehicle light that could be mostly related to their highest volatile substances ratio and smallest particle size. Thus, according to analysing the diameters of more than 1000 particles for each sample, the average diameter of fresh PMs can be enlarged from 21.2 to $30.4 \mathrm{~nm}$ due to the impact of vehicle light, while the aged PMs of DPF and gasoline vehicle exhaust pipe receive less enlargement impact ( 32.3 to $33.5 \mathrm{~nm}$ and 27.1 to $29.8 \mathrm{~nm}$, respectively).

\section{CONCLUSIONS}

We have seen that vehicle light has the potential to significantly change the nanostructure of primary particles by reductions in fringe length and fringe tortuosity (more straight carbon layers), and enlargements in fringe separation distance and core size/shell size and core size/particle size ratios for all three samples tested. Since the fresh PMs receive the highest changes in nanostructure as well as having the highest volatile components ratio and the smallest diameter, their average diameter can be enlarged from 21.2 to $30.4 \mathrm{~nm}$ due to the impact of vehicle light, while the aged PMs of diesel particulate filter and gasoline vehicle exhaust pipe receive less enlargement impact (32.3 to $33.5 \mathrm{~nm}$ and 27.1 to $29.8 \mathrm{~nm}$, respectively). When there are changes in the nanostructure and size for the particles, the other properties (physicochemical and cell toxicity) of these particles could be also affected, resulting in having positive and negative impacts on human health and the environment. For instance, the latest research and review studies published in 2020-2021 [14], [24] observed the reduction in the diameters of the particles causes an increase in the negative impact of PM cell toxicity properties on human and animal health. Obtaining further information about the impact of different types of vehicle headlights under various conditions and PM sources 
on the physicochemical and cell toxicity properties of PMs to realize the best type of vehicle headlight regarding its lower negative influence on human health and the environment will be our future task.

\section{ACKNOWLEDGEMENT}

This work was supported in part by the University of Macau under UM Macao Talent Programme (UMMTP-2019-02).

\section{REFERENCES}

[1] World Health Organization (WHO), World health statistics overview 2019: Monitoring health for the SDGs, sustainable development goals. WHO/DAD/2019.1, 2019. https://www.who.int. Accessed on: 22 Jul. 2021.

[2] World Health Organization (WHO), Ambient (outdoor) air pollution, 2018. https://www.who.int/news-room/fact-sheets/detail/ambient-(outdoor)-air-quality-andhealth. Accessed on: 22 Jul. 2021.

[3] World Health Organization (WHO), 9 out of 10 people worldwide breathe polluted air, but more countries are taking action, 2018. https://www.who.int/news-room/detail/0205-2018-9-out-of-10-people-worldwide-breathe-polluted-air-but-more-countries-aretaking-action. Accessed on: 22 Jul. 2021.

[4] Health Effects Institute, State of global air 2019: A special report on global exposure to air pollution and its disease burden, 2019. www.stateofglobalair.org. Accessed on: 22 Jul. 2021.

[5] Ghadikolaei, M.A., Wong, P.K., Cheung, C.S., Ning, Z., Yung, K.F., Zhao, J., Gali, N.K. \& Berenjestanaki, A.V., Impact of lower and higher alcohols on the physicochemical properties of particulate matter from diesel engines: A review. Renewable and Sustainable Energy Reviews, 143, 110970, 2021.

[6] Gangwar, R.S., Bevan, G.H., Palanivel, R., Das, L. \& Rajagopalan, S., Oxidative stress pathways of air pollution mediated toxicity: Recent insights. Redox Biology, 34, $101545,2020$.

[7] Akhtar, U.S., Rastogi, N., McWhinney, R.D., Urch, B., Chow, C.W., Evans, G.J. \& Scott, J.A., The combined effects of physicochemical properties of size-fractionated ambient particulate matter on in vitro toxicity in human A549 lung epithelial cells. Toxicology Reports, 1, pp. 145-156, 2014.

[8] Shin, S.W., Song, I.H. \& Um, S.H., Role of physicochemical properties in nanoparticle toxicity. Nanomaterials, 5(3), pp. 1351-1365, 2015.

[9] Dockery, D.W., Pope, C.A., Xu, X., Spengler, J.D., Ware, J.H., Fay, M.E., Ferris, B.G. \& Speizer, F.E., An association between air pollution and mortality in six U.S. cities. The New England Journal of Medicine, 329, pp. 1753-1759, 1993.

[10] Gauderman, W.J., Avol, E., Gilliland, F., Vora, H., Thomas, D., Berhane, K., McConnell, R., Kuenzli, N., Lurmann, F., Rappaport, E., Margolis, H., Bates, D. \& Peters, J., The effect of air pollution on lung development from 10 to 18 years of age. The New England Journal of Medicine, 351, pp. 1057-1067, 2004.

[11] Katsouyanni, K., Touloumi, G., Samoli, E., Gryparis, A., Le Tertre, A., Monopolis, Y., Rossi, G., Zmirou, D., Ballester, F., Boumghar, A., Anderson, H.R., Wojtyniak, B., Paldy, A., Braunstein, R., Pekkanen, J., Schindler, C. \& Schwartz, J., Confounding and effect modification in the short-term effects of ambient particles on total mortality: results from 29 European cities within the APHEA2 project. Epidemiology, 12(5), pp. 521-531, 2001. 
[12] Neer, A. \& Koylu, U.O., Effect of operating conditions on the size, morphology, and concentration of submicrometer particulates emitted from a diesel engine. Combustion and Flame, 146, pp. 142-154, 2006.

[13] Rohani, B. \& Bae, C., Morphology and nano-structure of soot in diesel spray and in engine exhaust. Fuel, 203, pp. 47-56, 2017.

[14] Chew, S., Kolosowska, N., Saveleva, L., Malm, T. \& Kanninen, K.M., Impairment of mitochondrial function by particulate matter: Implications for the brain. Neurochemistry International, 135, 104694, 2020.

[15] Finlayson-Pitts, B.J., Wingen, L.M., Perraud, V. \& Ezell, M.J., Open questions on the chemical composition of airborne particles. Communications Chemistry, 3, 108, 2020.

[16] Fuzzi, S., Baltensperger, U., Carslaw, K., Decesari, S., Denier van der Gon, H., Facchini, M.C., Fowler, D., Koren, I., Langford, B., Lohmann, U., Nemitz, E., Pandis, S., Riipinen, I., Rudich, Y., Schaap, M., Slowik, J.G., Spracklen, D.V., Vignati, E., Wild, M., Williams, M. \& Gilardoni, S., Particulate matter, air quality and climate: lessons learned and future needs. Atmospheric Chemistry and Physics, 15, pp. 82178299, 2015.

[17] Kumar, P., Kalaiarasan, G., Porter, A.E., Pinna, A., Kłosowski, M.M., Demokritou, P., Chung, K.F., Pain, C., Arvind, D.K., Arcucci, R., Adcock, I.M. \& Dilliway, C., An overview of methods of fine and ultrafine particle collection for physicochemical characterisation and toxicity assessments. Science of The Total Environment, 756, 143553, 2021.

[18] Weitekamp, C.A., Kerr, L.B., Dishaw, L., Nichols, J., Lein, M. \& Stewart, M.J., A systematic review of the health effects associated with the inhalation of particlefiltered and whole diesel exhaust. Inhalation Toxicology, 32(1), pp. 1-13, 2020.

[19] Wang, Y., Kamp, C.J., Wang, Y., Toops, T.J., Su, C., Wang, R., Gong, J. \& Wong, V.W., The origin, transport, and evolution of ash in engine particulate filters. Applied Energy, 263, 114631, 2020.

[20] Lapuerta, M., Rodríguez-Fernández, J. \& Sánchez-Valdepeñas, J., Soot reactivity analysis and implications on diesel filter regeneration. Progress in Energy and Combustion Science, 78, 100833, 2020.

[21] Mao, D., Ghadikolaei, M.A., Cheung, C.S., Shen, Z., Cui, W. \& Wong, P.K., Influence of alternative fuels on the particulate matter micro and nano-structures, volatility and oxidation reactivity in a compression ignition engine. Renewable and Sustainable Energy Reviews, 132, 110108, 2020.

[22] Ghadikolaei, M.A., Wei, L., Cheung, C.S., Yung, K.F. \& Ning, Z., Particulate emission and physical properties of particulate matter emitted from a diesel engine fueled with ternary fuel (diesel-biodiesel-ethanol) in blended and fumigation modes. Fuel, 263, 116665, 2020.

[23] Moffat, R.J., Describing the uncertainties in experimental results. Experimental Thermal and Fluid Science, 1(1), pp. 3-17, 1988.

[24] Rossi, S., Buccarello, A., Malvezzi, C.C., Pinelli, S., Alinovi, R., Gerboles, A.G., Rozzi, G., Leonardi, F., Bollati, V., Palma, G.D., Lagonegro, P., Rossi, F., Lottici, P.P., Poli, D., Statello, R., Macchi, E. \& Miragoli, M., Exposure to nanoparticles derived from diesel particulate filter equipped engine increases vulnerability to arrhythmia in rat hearts. Environmental Pollution, 284, 117163, 2021. 